\title{
Detecting Financial Stability Vulnerabilities in Due Time: Can Simple Indicators Identify a Complex Issue?
}

This paper analyzes the resilience of credit institutions to instances of financial instability based on simple publicly available balance sheet and income statement figures. In the course of the recent financial crisis and the related credit turmoil, the loss absorption capacity of the global financial system has been stretched to its limit. Globally active financial institutions, many of them systemically relevant, needed government support to keep their capital ratios above regulatory and/or market required minima. Central banks had to step in to provide liquidity when large parts of the financial markets ceased to function. From an ex-post perspective, the crisis provided a real stress scenario which we use to explain bank performance by examining simple indicators such as capitalization, liquidity, funding structure and asset-side exposure. To cover systemically important European banks we choose a subset from the bank sample used by the European Banking Association for the EU-wide stresstesting exercise in 2011. We add three Austrian banks to arrive at a sample of 90 European banks in total (including altogether six Austrian banks). To measure bank performance, we use return on average assets, return on average equity, operating profits, required government support and equity prices. We show that these performance measures can be explained adequately by our simple indicators. We are able to identify the strong, respectively weak, banks that did not, respectively did, need government support in 2009. Regarding the other performance measures we give a forecast for 2011 about which banks are expected to perform well, ordinarily and poorly.

JEL classification: E44, E32, E37

Keywords: bank performance, financial crisis, stress testing, early warning

\section{Motivation}

The recent global financial crisis turned public, political and academic attention to the development of early warning indicators for banks' resilience to instances of financial instability. This is a growing policy concern also in Europe, as highlighted by the EU-wide stresstesting exercise coordinated by the newly established European Banking Authority (EBA) in 2011. Academic interest typically focusses on early warning indicators in the aftermath of banking crises.

Any study on bank resilience must address a number of complex issues: How can bank performance and resil- ience be measured in a meaningful way and what kind of variables do influence them? Which indicators deliver robust results that can be used as early warning signals? And how to deal with the creative tension between complex models that account for the limited availability of timely data and simpler models applying lower data standards?

\subsection{Defining Bank Performance}

In the literature, it is an established practice to use bank performance as a general indicator for bank resilience. ${ }^{2}$ Measuring bank performance, however, is not a straightforward exercise as banks may differ substantially in their
Benjamin

Neudorfer,

Michael Sigmund,

Alexander Trachta ${ }^{1}$

\footnotetext{
Oesterreichische Nationalbank, Financial Markets Analysis and Surveillance Division, Benjamin.Neudorfer@oenb.at,Michael.Sigmund@oenb.at,Alexander.Trachta@oenb.at. The authors are grateful for helpful discussions with Claus Puhr and Stefan W. Schmitz.

2 See Demirguc-Kunt et al. (2010), Ratnovski and Huang (2009) and Bologna (2010). As an alternative, Sun (2011) and Poghosyan and Cihak (2009) use expected default frequencies provided by Moody's KMV model to quantify bank resilience.
} 
risk-taking profile. As long as markets work properly, bank performance needs to be risk-adjusted to serve as a meaningful indicator since risk and return are correlated. Otherwise, there is the danger that excessive risktaking might go unnoticed in good times, since potential flaws in flat riskweighted assets for certain sectors as well as toxic assets, misleading ratings, lenient provisioning policies and looser lending standards cannot be detected easily.

As Poghosyan and Cihak (2009) point out, up to the recent crisis Europe has seen only a small number of outright bank failures, which makes it very difficult from a statistical point of view to estimate and calibrate early warning models to be used in banking supervision. Although the deep current crisis has put many European banks on the brink of insolvency, government intervention has saved many institutions from failure. To solve the econometrical problem of having too few actual bank failures to draw from, Ratnovski and Huang (2009) suggest to measure bank performance by a dummy variable which indicates government support in response to extreme stress.

In our study we measure bank performance by different performance indicators such as equity price changes, government support and return on average assets.

\subsection{Explaining Bank Performance}

After defining bank performance, we must find variables that explain bank performance. With respect to the trade-off between model complexity and data availability, we follow Rat- novski and Huang (2009) and Sun (2011) and test the hypothesis that simple publicly available balance sheet data serve as good explanatory variables to identify weak banks. ${ }^{3}$

Moreover, Poghosyan and Cihak (2001) report that well established complex indicators such as capital, asset quality, management quality as well as equity and liquidity grades are somewhat limited when it comes to predicting bank failures and therefore need to be complemented by other indicators.

To control for the robustness of our results, we test our set of indicators based on a sample of international banks without regard to institutionspecific data. After all, any bank resilience analysis boils down to classifying a sample of banks into weak and sound institutions. Only a few papers have addressed the topic of resilience indicators based on the recent global financial crisis, i.a. Poghosyan and Cihak (2009) and Beltratti (2009). We hope the approach we suggest proves useful in enhancing supervisors' abilities to take a more forward-looking view on banks.

\section{Data}

To test our hypothesis, we analyze annual balance sheet and income statement data obtained from Bankscope and some additional market data obtained from Bloomberg. Our sample covers 90 banks from 21 European countries ${ }^{4}$. The sample largely mimics the EBA sample used for the EU-wide stress-testing exercise conducted in July 2011. The banks in the EBA sample account for over $65 \%$ of the EU banking system's total assets and for at least $50 \%$ of total consolidated assets

\footnotetext{
Our dataset consists of annual balance and income statement data derived from the financial statements of banks made available through the Bankscope database of Bureau van Dijk.

4 Austria, Belgium, Cyprus, Germany, Denmark, Spain, Finland, France, United Kingdom, Greece, Hungary, Ireland, Italy, Luxembourg, Malta, Netherlands, Norway, Poland, Portugal, Sweden and Slovenia.
} 
of the national banking sectors in each EU Member State at the end of 2010. In our subset of this sample, we had to exclude some smaller Spanish banks (cajas) as for these, some data relevant to our methodology are not available. $^{5}$

In addition, to improve the robustness and check the plausibility of our results we apply our estimation methodology to an enlarged bank sample of 957 consolidated banks from various OECD countries, with each bank's total assets coming to over EUR 5 billion as of end-2010.

We selected our endogenous (performance) and exogenous (explanatory) variables based on related literature and with respect to the following criteria: comparability of results, data availability.

\subsection{Variables to Measure Bank Performance}

Following the standard literature on bank performance, we look at the return on average assets $(\mathrm{ROAA}=$ net income divided by average total assets) and the return on average equity $(\mathrm{ROAE}=$ net income divided by average total equity). The ROAA shows a bank's profitability before leverage, while the ROAE is an easily comparable profitability measure of shareholder value. In the literature, the ROAA is widely perceived to be valuable as a profitability and performance indicator since it is adjusted for the leverage effect. For this reason, focusing on the ROAE alone might sometimes render misleading results (Sun, 2011).

The second pair of performance measures are two variables derived from the income statement, namely operating profits (after impairments), adjusted both for risk-weighted assets (RWA) and total assets, (operating profits divided by RWA; operating profits divided by total assets) to differentiate between risk weight-adjusted and non-risk weight-adjusted profitability ratios. ${ }^{6}$

Next, we include the relative yearon-year equity price change using yearend data. ${ }^{7}$ According to Ratnovski and Huang (2009), the decline in equity prices serves as a credible performance measure since it includes credit losses, securities write-downs and dilution from new equity issuances including government capital injections.

The last performance measure we include is a dummy variable that captures government intervention during crisis periods. Here, we include banks that have received capital injections (excluding temporary central bank liquidity injections), loans or similar support vehicles or have been nationalized or merged during the crisis to avoid bankruptcy.

\subsection{Variables Used to Explain Bank Performance}

As explanatory variables we use a set of balance sheet and income statement variables. Three of our 13 explanatory variables mimic the ratios used by Ratnovski and Huang (2009). We include additional publically available variables to capture different areas of balance sheet fundamentals to improve the predictive power of the model.

To assess asset quality, we first proxy the flows in loan loss provisions (LLP) and use Bankscope stock data on impairment flows divided by total as-

In 2009 and 2010, the Spanish banking sector was significantly restructured.

6 Operating profits and net income are both risk adjusted with respect to impairments.

In our performance variable selection we also compare year-end data with average December stock prices. Both measures provide very similar results. 
sets as a proxy for nonperforming loans (NPLs). To measure the unexpected loss potential of banks' total portfolio we divide RWA by total assets. For capitalization we use a simple ratio of total balance sheet equity to total assets. To account for different bank business models (e.g. investment and universal banks), we assess the effects of banks' income structure on their resilience. Therefore, we include the ratio of net interest income to total assets and the ratio of non-interest operating income to total assets as explanatory variables. Concerning funding and liquidity, we look at the ratios of liquid assets ${ }^{8}$ to total assets and customer deposits to total assets as used by Ratnovski and Huang (2009) in their analysis. We enhance these variables by the loan-to-customer deposit ratio (LDR) and long-term funding divided by total assets. To capture the portfolio structure of the observed banks, we use the ratios of relative trading book size to total assets and loan growth.

\section{Empirical Analysis}

In this section, we outline the econometric theory and estimation procedures behind our models to explain the different bank performance measures outlined in the data section. As stated in the introduction, we intend to answer the question of what kind of variables influence the status of the bank performance measure as a proxy for bank resilience. In line with a number of related papers on bank performance such as Sun (2011), we choose a panel model approach to link our perfor- mance measures to balance sheet and income statement positions. ${ }^{9}$

We start from a model in which all coefficients are the same across individual banks and time, except the intercept term.

$$
y_{i, t}=\alpha_{i}+x_{i, t-1}^{\prime} \beta+u_{i, t}
$$

It is assumed that $u_{i, t} \sim N\left(0, \sigma_{u}^{2}\right)$ is independent of all $x_{i, t}$. Aside from these standard technical details, two further important remarks are necessary. First, we regress the current bank performance measure $y_{i, t}$ on past balance sheet and income statement variables. This approach avoids endogeneity problems, helps identify problem banks based on their past balance and income statement structure and serves as a prerequisite for early warning indicators. Second, we fix $\beta_{i}=\beta$ for all banks within our sample. This implies that the slope coefficients are supposed to be identical for all institutions and time periods. The most important advantage of panel models relates to the model intercept $\alpha_{i}$. As pointed out by Verbeek (2008), the availability of panel data will ease the problem of distinguishing between true and spurious state dependence, because individual histories are observed and can be included in the analysis. An individual specific intercept term allows controlling for unobserved variables such as management quality, bank business models and other bank-specific characteristics that are time invariant at least for the time span observed. For this paper we analyze in detail the influence of our explanatory

\footnotetext{
8 The Bankscope position of liquid assets is harmonized for different jurisdictions and includes trading securities at fair value, cash, reverse repos and collateral and short-term claims on other banks.

9 Referring to Verbeek (2008), panel models have two major advantages over models using only time series or cross sections, namely the efficiency of parameter estimation and the improved identification of parameters. We do not consider lags of higher order as we assume that the history of all past management decisions is reflected in the previous year's balance sheet and the resulting income statement structure.
} 
variables on the return on average assets, on government support and equity prices. $^{10}$

\subsection{Return on Average Assets}

First, we look at the ROAA as a performance measure. ${ }^{11}$ In a series of tests, we come to the conclusion to reject the poolability hypothesis of our data sample. Following the standard literature on static panel econometrics, we are left with two options concerning: considering fixed effects or random effects. A Hausmann test implies that only the fixed-effect model provides consistent results. ${ }^{12}$

Table 1 in the annex reveals interesting empirical results. After controlling for several variables, three of the chosen variables show economic and statistical significance. The loan impairment charge ratio as a proxy for the LLP flow ratio lagged by one period has a significant negative influence on the current ROAA. The same holds true for net interest income ratio and the noninterest income ratio.

To test for the robustness of the insignificant RWA ratio, we estimated two further panel models with the same exogenous variables as listed in table 1, but using operating profits divided by total assets and operating profits divided by RWA as performance measures. The operating profits-di- vided-by-total assets model gives a much better fit, indicating that RWA might not mirror economic risk in a meaningful way. ${ }^{13}$ The fact that the influence of the leverage ratio (equity divided by total assets) on the ROAA is insignificant seems to be a surprising result at first glance. Since the balance sheet position "equity" does not distinguish between types of capital, "equity" does not include any information on capital quality (e.g. risk-bearing capacity). If the value for equity in the balance sheet equity is high, this does not necessarily signal that the respective institution is particularly crisis resilient, as pointed out by Sun (2011).

In contrast to Ratnovski and Huang (2009), neither the ratio of long-term funding to total assets, the ratio of depository funding to total assets nor the loan-to-deposit ratio have a significant influence on the ROAA in the subset of the EBA bank sample we use here. These surprising findings - no influence of long-term funding and depository funding on ROAA - could be explained by the fact that banks had access to ECB tenders during the crisis years, which means that banks with a riskier (short-term) funding structure, which relied mostly on the interbank market, were able to easily gain access to (unlimited) ECB tenders. ${ }^{14}$ Finally, we could not provide empirical evi-

${ }^{10}$ The additional performance measures ROAE, operating income divided by total assets and operating income divided by RWA are used to check for the plausibility and robustness of the results obtained for the other three performance measures. On the one hand, ROAE is similar to ROAA except for the leverage effect and on the other hand, the operating income-related variables are used to analyze the importance of RWAs. The results of the additional performance measures are provided in tables 4, 5 and 6 in the annex.

${ }^{11}$ All estimations are carried out by the statistical software $R$ and Stata.

${ }^{12}$ The same test procedure, ranging from poolability test to Hausmann test, is applied to all other performance measure estimations.

${ }^{13}$ Our result is in line with Sun (2011), who claims the RWA ratio is not always a useful indicator since there are difficulties in determining the unexpected loss potential of assets, accounting for deficiencies in mark-to-market accounting practices and locating assets and contingent claims (e.g. derivatives) in off-balance sheet vehicles where they can receive lower risk weights.

${ }^{14}$ In an additional panel model, we extended our bank sample to 957 OECD banks and find significant positive influence of the long-term funding and customer deposits-to-total asset ratio on the ROAA. 
dence that the liquid asset ratio is a prominent factor in explaining the ROAA. ${ }^{15}$

\subsection{Government Support}

Table 2 in the annex shows our estimation outcome for the government support dummy in a linear panel probability model. ${ }^{16}$ The positive coefficient for our loan loss provision ratio (LLPR) flow for the last period observed implies that the probability of government support increases. In contrast to the ROAA results, the total equity ratio is found to have a significant negative influence on government support, which implies that better capitalized banks were less likely to receive government support. The same holds true for the total noninterest operating income ratio and the liquid asset ratio. Surprisingly, the trading book ratio initially included into the estimation to control for banks' portfolio structure has a significantly negative sign, which ceteris paribus reduces the influence of the total noninterest operating income ratio on the probability of government support.

\subsection{Equity Price Change}

In contrast to the previous tables, table 3 in the annex shows hardly any signifi- cant explanatory variables that predict the relative year-on-year equity price change. ${ }^{17}$ Only the total equity ratio is found to have a significantly positive influence on the equity price change. Moreover, the overall explanatory power of the model is relatively low. ${ }^{18}$ We think a couple of arguments might support our findings. First, the equity price change might not be the best market-based indicator for bank performance. ${ }^{19}$ Second, we apply a different methodology than Ratnovski and Huang (2009) to classify banks according to their equity price performance. Third, equity prices are expected to be forward looking, which implies that balance sheet and income statement developments are priced in instantaneously to avoid arbitrage opportunities. Finally, the highly significant year dummies ${ }^{20}$ point toward herding behavior, especially in periods of crisis and euphoria.

\section{Early Warning Results}

In this section we provide some evidence for the predictive power of our models to indicate whether they may serve as macroprudential early warning tools. First, we use the government support model to predict - for each

\footnotetext{
15 Again, Ratnovski and Huang (2009) come up with a significant result. We think that their results are dominated by a special characteristic of the Canadian banking system, namely the liquidity guidelines stating that banks have to maintain a stock of highly liquid assets appropriate for their cash flow and funding profile.

${ }^{16}$ As we model government support as a binary variable, a correctly specified probability model would require a logit or probit transformation to ensure that the estimated probability of government support lies within the interval $(0,1)$. However, especially in fixed-effect models, a couple of statistical problems with logit or probit transformations arise. E.g. for a fixed number of time periods and $N \rightarrow \infty$, the problem of incidental parameters makes an (unconditional) maximum likelihood estimation inconsistent because the number of unknown parameters grows with the sample size. As a consequence, we stick to the linear panel probability model and compare our results with probit-transformed random effect models to ensure robustness.

17 Similar results are observed when using both year-end stock prices and average December prices.

${ }^{18}$ For the enlarged OECD bank sample we obtain slightly different results. Here, only the LLPR flow is significant at the 1\% level with a somehow surprisingly positive coefficient. The overall fit is even worse than in the sample of European banks.

19 See also Sun (2011), who uses the price-to-earnings ratio and the earnings and book values per share in his model.

${ }^{20}$ Year dummies refer to the level of each year's specific intercept, which means that by using these variables we account for developments that took place in the European market in the specific year.
} 
bank - the probability of receiving government support (for the 90 European sample banks) in 2009 by applying lagged balance sheet and income statement variables from 2008. We rank the sample according to the probability distribution of the model output, where the first quartile is supposed to represent the most resilient banks and the last quartile the banks most likely to receive government support in the following year. The results of our model are in line with banks' actual performance during the crisis. In the first quartile, 16 of a total of 17 banks did not receive government support while in the fourth quartile, 14 of a total of 17 banks received government support in 2009. ${ }^{21}$

In the sample forecast of the ROAA, our model performed slightly less successfully, which can be attributed to the fact that, unlike government support, the ROAA is a continuous variable. Nevertheless, the model succeeds in identifying more than $60 \%$ of both the strongest and weakest banks. The out-of-sample ROAA forecast for end2011 shows reasonable results. On the one hand, banks with a relatively low predicted ROAA broadly correspond with banks that showed negative results in their interim statements 2011. On the other hand, banks with low predicted returns are mostly located in countries that are perceived to experience adverse macroeconomic developments in 2011. This shows that the proposed models qualify as effective early warning tools.

\section{Conclusions}

In this paper we establish potential early warning tools for analyzing bank performance and contribute to the pre- vious literature on bank performance by explaining different performance measures with the help of simple and publically available balance sheet and income-based variables and by comparing these measures.

Among the standard bank performance measures, our fixed explanatory variable set yields better results in explaining the ROAA than both the ROAE and equity price changes. The financial crisis provided a real adverse scenario that created an additional bank performance variable, namely the injection of government support capital.

Our explanatory variables capture different areas of balance sheet and income statement fundamentals. To a certain extent our method makes it possible to predict future banking performance using only a limited number of selected explanatory variables. The part of the model that is based on government support figures provides an accurate in-sample forecast for receiving government support in 2009.

Concerning the significance of the explanatory variables, we find differences among the performance measures. The probability of receiving government support and the ROAA are significantly influenced by the LLP flow ratio, by net interest income and the total noninterest income ratio. The balance sheet equity ratio and liquid asset ratio are found to only influence the probability of government support.

The funding-related variables (longterm funding and depository funding) appear not to be significant for government support and the ROAA in the sample of European banks. One explanation of this counter-intuitive result might be that mitigating actions by central banks, i.e. ample provision of

${ }^{21}$ According to the model, Austrian banks belong in the second and third quartiles with government support probabilities ranging between $27 \%$ and $54 \%$. 
liquidity, prevented the differences in bank performance between the banks in the sample to fully play out.

We also looked beyond mere structural ratios into banks' asset side. Interestingly, we found that in our bank sample the RWA ratio does not significantly influence any of the performance measures. This raises the question of whether RWA capture economic risk appropriately.
When explaining equity price changes, only a few exogenous variables apart from the year dummies seem to be significant. The year dummies are found to be highly significant for European banks and for the enlarged OECD control sample. This leads us to the conclusion that equity prices are dominated mostly by the overall market environment and do not reflect idiosyncratic bank characteristics very accurately.

\section{References}

Banachewicz, K., Lucas, A. and A. Van der Vaart. 2008. Modelling portfolio defaults using hidden Markov models with covariates. In: Econometrics Journal 11(1). 155-171.

Bank for International Settlements. 2010. Basel III: A Global Regulatory Framework for more Resilient Banks and Banking Systems.

Berger, A. and G. Udell. 2004. The institutional memory hypothesis and the procyclicality of bank lending behavior. In: Journal of Financial Intermediation 13(4). 458-495.

Beltratti, P. 2009. Why did some banks perform better during the crisis? A cross-country study of the impact of governance and regulation. National Bureau of Economic Research 15180.

Bologna, P. 2010. Australian banking system resilience: What should be expected looking forward? An international perspective. International Monetary Fund WP/10/228.

Demirguc-Kunt, A., Detragiache, E. and O. Merrouche. 2010. Bank capital: Lessons from the financial crisis. International Monetary Fund WP/10/286.

Poghosyan, T. and M. Cihak. 2001. Rating banks in emerging markets: What credit rating agencies should learn from financial indicators. Peterson Institute for International Economics WP01/6.

Poghosyan, T. and M. Cihak. 2009. Distress in European banks: An analysis based on a new data. International Monetary Fund WP/09/9.

Ratnovski, L. and R. Huang. 2009. Why Are Canadian Banks More Resilient. International Monetary Fund WP/09/152.

Sun, T. 2011. Identifying vulnerabilities in systemically-important financial institutions in a macrofinancial linkages framework. International Monetary Fund WP/11/111.

Verbeek, M. 2008. A guide to modern econometrics. John Wiley and Sons. $3^{\text {rd }}$ edition. 


\section{Annex}

\section{Return on Average Assets}

$$
\begin{array}{l|l|l|l}
\text { Estimate } & \text { Standard error } & \text { t-value } & \text { p-value }
\end{array}
$$

Sample of European banks (90 banks)

Lag(LoanlmpairmentCharge/TotalAssets,1) Lag(ProxyNPLStock/TotalAssets,1)

Lag(TotalEquity/TotalAssets,1)

Lag(RWAs/TotalAssets,1)

Lag(NetInterestIncome/TotalAssets,1)

Lag(TotalNonlnterestOplncome/TotalAssets,1)

Lag(LiquidAssets/TotalAssets,1)

Lag(TotalCustomerDeposits/TotalAssets,1)

Lag(Longtermfunding/TotalAssets,1)

Lag(Loan.CustomerDeposit,1)

Lag(ProxyTradingBook/TotalAssets,1)

Lag(GrossLoanGrowth,1)

Year dummy for 2007

Year dummy for 2008

Year dummy for 2009

Year dummy for 2010

\begin{tabular}{|r|r|r|l|}
\hline-118.5035 & 15.4221 & -7.68 & $0.0000 * * *$ \\
8.5323 & 5.6812 & 1.50 & 0.1351 \\
1.5883 & 6.1111 & 0.26 & 0.7953 \\
-1.0430 & 0.7350 & -1.42 & 0.1578 \\
71.0205 & 17.4660 & 4.07 & $0.0001 * * *$ \\
29.0752 & 13.4458 & 2.16 & $0.0321 *$ \\
1.1193 & 1.0301 & 1.09 & 0.2788 \\
-0.6100 & 1.3829 & -0.44 & 0.6598 \\
1.5505 & 0.9892 & 1.57 & 0.1190 \\
0.1315 & 0.0751 & 1.75 & 0.0819 \\
1.0851 & 1.0147 & 1.07 & 0.2865 \\
0.0855 & 0.2094 & 0.41 & 0.6837 \\
-0.7547 & 1.0464 & -0.72 & 0.4720 \\
-1.2317 & 0.0901 & -5.29 & $0.0000 * * *$ \\
-1.7087 & 0.1308 & -2.60 & $0.0100 *$ \\
-2.1857 & 0.1557 & -0.33 & 0.7440 \\
\hline 0.5266 & 0.1366 & 0.3469 & \\
\hline 70 & 247 & & \\
\hline 4 & & & \\
\hline
\end{tabular}

Root-squared: within, between and overall

Number of groups and observations

From 2007 to 2010

Source: Authors' calculations.

Note: Significance codes: $0.001=* * *, 0.01=* *, 0.05=*, 0.1=\bullet$

\section{Government Support}

\begin{tabular}{l|l|l|l} 
Estimate & Standard error & t-value & P-value
\end{tabular}

Sample of European banks (90 banks)

Lag(LoanImpairmentCharge/TotalAssets,1) Lag(ProxyNPLStock/TotalAssets,1)

Lag(TotalEquity/TotalAssets,1)

Lag(RWAs/TotalAssets,1)

Lag(NetInterestIncome/TotalAssets,1)

Lag(TotalNonInterestOplncome/TotalAssets,1)

Lag(LiquidAssets/TotalAssets,1)

Lag(TotalCustomerDeposits/TotalAssets,1)

Lag(Longtermfunding/TotalAssets,1)

Lag(Loan.CustomerDeposit,1)

Lag(ProxyTradingBook/TotalAssets,1)

Lag(GrossLoanGrowth,1)

Year dummy for 2007

Year dummy for 2008

Year dummy for 2009

Year dummy for 2010

Root-squared: within, between and overall

Number of groups and observations

From 2007 to 2010

\begin{tabular}{|c|c|c|c|}
\hline 24.8513 & 7.6571 & 3.25 & $0.0014 * *$ \\
\hline 3.6956 & 2.8886 & 1.28 & 0.2025 \\
\hline-8.2203 & 3.1832 & -2.58 & $0.0107 *$ \\
\hline-0.0245 & 0.3932 & -0.06 & 0.9504 \\
\hline-8.0598 & 9.6317 & -0.84 & 0.4039 \\
\hline-18.2033 & 6.9452 & -2.62 & $0.0096 * *$ \\
\hline-1.5832 & 0.5126 & -3.09 & 0.0024 ** \\
\hline 0.3265 & 0.7796 & 0.42 & 0.6759 \\
\hline-1.0287 & 0.5444 & -1.89 & $0.0605 \bullet$ \\
\hline 0.0333 & 0.0422 & 0.79 & 0.4316 \\
\hline-1.7152 & 0.5637 & -3.04 & $0.0027 * *$ \\
\hline-0.2374 & 0.1134 & -2.09 & $0.0379 *$ \\
\hline- & - & - & - \\
\hline- & - & - & - \\
\hline- & - & - & - \\
\hline - & - & - & - \\
\hline 0.4794 & 0.2031 & 0.2492 & \\
\hline $\begin{array}{r}71 \\
4\end{array}$ & 252 & & \\
\hline
\end{tabular}

Source: Authors' calculations.

Note: Significance codes: $0.001=* * *, 0.01=* *, 0.05=*, 0.1=$ 


\section{Equity Price Change}

\begin{tabular}{|c|c|c|c|c|}
\hline & Estimate & Standard error & t-value & p-value \\
\hline \multicolumn{5}{|l|}{ Sample of European banks (90 banks) } \\
\hline Lag(LoanlmpairmentCharge/TotalAssets,1) & -4.8091 & 10.4480 & -0.46 & 0.6463 \\
\hline Lag(ProxyNPLStock/TotalAssets,1) & 0.5525 & 4.3886 & 0.13 & 0.9001 \\
\hline Lag(TotalEquity/TotalAssets,1) & 10.2260 & 4.5980 & 2.22 & $0.0283 *$ \\
\hline Lag(RWAs/TotalAssets,1) & -0.0514 & 0.5635 & -0.09 & 0.9275 \\
\hline Lag(NetInterestIncome/TotalAssets,1) & -3.3542 & 12.1735 & -0.28 & 0.7834 \\
\hline Lag(TotalNonInterestOplncome/TotalAssets,1) & 14.3501 & 12.5364 & 1.14 & 0.2549 \\
\hline Lag(LiquidAssets/TotalAssets,1) & 0.4465 & 0.7776 & 0.57 & 0.5670 \\
\hline Lag(TotalCustomerDeposits/TotalAssets,1) & -1.2442 & 1.0460 & -1.19 & 0.2369 \\
\hline Lag(Longtermfunding/TotalAssets,1) & -0.1519 & 0.7169 & -0.21 & 0.8326 \\
\hline Lag(Loan.CustomerDeposit,1) & 0.0197 & 0.0494 & 0.40 & 0.6909 \\
\hline Lag(ProxyTradingBook/TotalAssets,1) & 0.2808 & 0.7298 & 0.38 & 0.7012 \\
\hline Lag(GrossLoanGrowth,1) & 0.2019 & 0.1435 & 1.41 & 0.1623 \\
\hline Year dummy for 2007 & -0.4089 & 0.7486 & -0.55 & 0.5860 \\
\hline Year dummy for 2008 & -0.9372 & 0.0689 & -7.67 & $0.0000 * * *$ \\
\hline Year dummy for 2009 & 0.2305 & 0.0983 & 6.51 & $0.0000 * * * *$ \\
\hline Year dummy for 2010 & -0.3685 & 0.1153 & 0.35 & 0.7270 \\
\hline Root-squared: within, between and overall & 0.7228 & 0.0698 & 0.5422 & \\
\hline $\begin{array}{l}\text { Number of groups and observations } \\
\text { From } 2007 \text { to } 2010\end{array}$ & $\begin{array}{r}46 \\
4\end{array}$ & 167 & & \\
\hline
\end{tabular}

\section{Return on Average Equity}

Sample of European banks (90 banks)

Lag(LoanlmpairmentCharge/TotalAssets,1)

Lag(ProxyNPLStock/TotalAssets,1)

Lag(TotalEquity/TotalAssets,1)

Lag(RWAs/TotalAssets,1)

Lag(NetInterestIncome/TotalAssets,1)

Lag(TotalNonInterestOplncome/TotalAssets,1)

Lag(LiquidAssets/TotalAssets,1)

Lag(TotalCustomerDeposits/TotalAssets,1)

Lag(Longtermfunding/TotalAssets,1)

Lag(Loan.CustomerDeposit,1)

Lag(ProxyTradingBook/TotalAssets, 1)

Lag(GrossLoanGrowth,1)

Year dummy for 2007

Year dummy for 2008

Year dummy for 2009

Year dummy for 2010

Root-squared: within, between and overall

Number of groups and observations

From 2007 to 2010

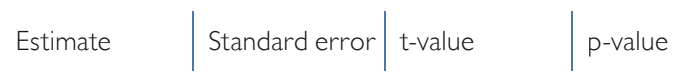

\begin{tabular}{|c|c|c|c|}
\hline$-2,362.5527$ & 609.2942 & -3.88 & 0.0002 **** \\
\hline 428.7573 & 224.4500 & 1.91 & $0.0579 \bullet$ \\
\hline 57.9417 & 241.4367 & 0.24 & 0.8106 \\
\hline 13.5442 & 29.0388 & 0.47 & 0.6415 \\
\hline $1,322.0367$ & 690.0451 & 1.92 & $0.0571 \bullet$ \\
\hline 679.3825 & 531.2135 & 1.28 & 0.2028 \\
\hline 19.4388 & 40.6963 & 0.48 & 0.6335 \\
\hline-48.1181 & 54.6359 & -0.88 & 0.3798 \\
\hline 30.5188 & 39.0819 & 0.78 & 0.4360 \\
\hline 3.7719 & 2.9667 & 1.27 & 0.2054 \\
\hline-20.4427 & 40.0873 & -0.51 & 0.6108 \\
\hline-29.4994 & 8.2746 & -3.57 & 0.0005 **** \\
\hline-10.9185 & 41.3429 & -0.26 & 0.7920 \\
\hline-25.2006 & 3.5604 & -4.01 & $0.0000 * * * *$ \\
\hline-22.5234 & 5.1692 & -2.25 & $0.0260 *$ \\
\hline-19.5475 & 6.1504 & -1.40 & 0.1630 \\
\hline 0.312 & 0.0014 & 0.0698 & \\
\hline $\begin{array}{r}70 \\
4\end{array}$ & 247 & & \\
\hline
\end{tabular}


Ratio of Operating Profit to Total Assets

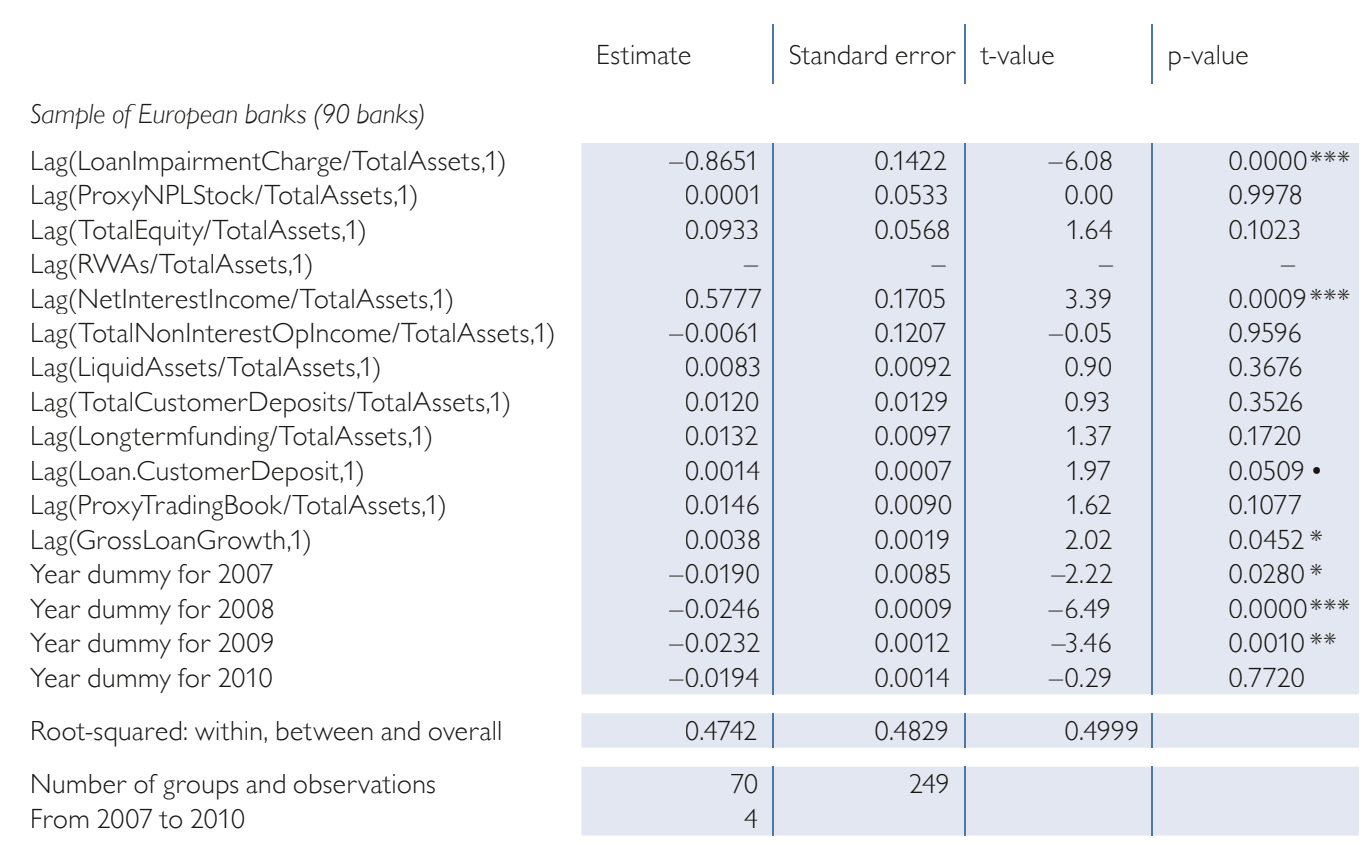

\section{Ratio of Operating Profit to Risk-Weighted Assets}

Sample of European banks (90 banks)

Lag(LoanImpairmentCharge/TotalAssets,1) Lag(ProxyNPLStock/TotalAssets, 1)

Lag(TotalEquity/TotalAssets,1)

Lag(RWAs/TotalAssets,1)

Lag(NetInterestlncome/TotalAssets,1)

Lag(TotalNonInterestOplncome/TotalAssets,1)

Lag(LiquidAssets/TotalAssets,1)

Lag(TotalCustomerDeposits/TotalAssets,1)

Lag(Longtermfunding/TotalAssets,1)

Lag(Loan.CustomerDeposit,1)

Lag(ProxyTradingBook/TotalAssets,1)

Lag(GrossLoanGrowth,1)

Year dummy for 2007

Year dummy for 2008

Year dummy for 2009

Year dummy for 2010

Root-squared: within, between and overall

$$
\begin{array}{l|l|l}
\text { Estimate } & \text { Standard error } \mid \text { t-value } \quad \text { p-value }
\end{array}
$$

Number of groups and observations

From 2007 to 2010

\begin{tabular}{|r|c|c|l|}
\hline 15.5571 & 10.1909 & 1.53 & 0.1288 \\
-4.3718 & 3.7577 & -1.16 & 0.2463 \\
3.6111 & 3.8726 & 0.93 & 0.3525 \\
- & - & - & - \\
9.4413 & 11.5288 & 0.82 & 0.4140 \\
-14.5574 & 8.7791 & -1.66 & $0.0992 \cdot$ \\
0.3312 & 0.6485 & 0.51 & 0.6102 \\
2.8747 & 0.9086 & 3.16 & $0.0019 * *$ \\
0.4440 & 0.6697 & 0.66 & 0.5082 \\
0.0747 & 0.0491 & 1.52 & 0.1301 \\
0.6973 & 0.6938 & 1.01 & 0.3164 \\
0.1228 & 0.1312 & 0.94 & 0.3505 \\
-1.7446 & 0.5996 & -2.91 & $0.0040 * *$ \\
-1.7297 & 0.0599 & 0.25 & 0.8040 \\
-1.8392 & 0.0838 & -1.13 & 0.2610 \\
-1.8511 & 0.0994 & -1.07 & 0.2850 \\
\hline 0.1193 & 0.1131 & 0.0596 & \\
\hline 70 & 249 & & \\
\hline 4 & & & \\
\hline & & & \\
\hline
\end{tabular}

Source: Authors' calculations.

Note: Significance codes: $0.001=* * *, 0.01=* *, 0.05=*, 0.1=\bullet$. 


\section{Return on Average Assets}

\begin{tabular}{|c|c|c|c|c|}
\hline & Estimate & Standard error & t-value & p-value \\
\hline \multicolumn{5}{|l|}{ Sample of OECD banks (957 banks) } \\
\hline $\begin{array}{l}\text { Lag(LoanImpairmentCharge/TotalAssets,1) } \\
\text { Lag(ProxyNPLStock/TotalAssets,1) } \\
\text { Lag(TotalEquity/TotalAssets,1) } \\
\text { Lag(RWAs/TotalAssets,1) } \\
\text { Lag(NetInterestIncome/TotalAssets,1) } \\
\text { Lag(TotalNonInterestOplncome/TotalAssets,1) } \\
\text { Lag(LiquidAssets/TotalAssets,1) } \\
\text { Lag(TotalCustomerDeposits/TotalAssets,1) } \\
\text { Lag(Longtermfunding/TotalAssets,1) } \\
\text { Lag(Loan.CustomerDeposit,1) } \\
\text { Lag(GrossLoanGrowth,1) } \\
\text { Year dummy for } 2007 \\
\text { Year dummy for } 2008 \\
\text { Year dummy for } 2009 \\
\text { Year dummy for } 2010\end{array}$ & \begin{tabular}{r|}
-83.1925 \\
12.9437 \\
-5.7711 \\
-0.7030 \\
35.6976 \\
5.3246 \\
1.3127 \\
2.6332 \\
2.5088 \\
0.0000 \\
0.0198 \\
-0.9392 \\
-1.3841 \\
-1.3984 \\
-1.1468
\end{tabular} & $\begin{array}{r}5.3625 \\
2.6189 \\
2.6482 \\
0.4937 \\
10.8601 \\
5.8989 \\
0.6502 \\
0.7192 \\
0.7652 \\
0.0001 \\
0.0964 \\
0.4998 \\
0.0796 \\
0.0902 \\
0.0964\end{array}$ & $\begin{array}{r}-15.51 \\
4.94 \\
-2.18 \\
-1.42 \\
3.29 \\
0.90 \\
2.02 \\
3.66 \\
3.28 \\
0.01 \\
0.21 \\
-1.88 \\
-5.59 \\
-5.09 \\
-2.15\end{array}$ & $\begin{array}{l}0.0000 * * * * \\
0.0000 * * * \\
0.0296 \text { * } \\
0.1548 \\
0.0011 * * \\
0.3670 \\
0.0438 \text { * } \\
0.0003 \text { *** } \\
0.0011 \text { ** } \\
0.9906 \\
0.8374 \\
0.0610 \text { • } \\
0.0000 * * * \\
0.0000 * * * \\
0.0320 *\end{array}$ \\
\hline Root-squared: within, between and overall & 0.3314 & 0.0476 & 0.159 & \\
\hline $\begin{array}{l}\text { Number of groups and observations } \\
\text { From } 2007 \text { to } 2010\end{array}$ & $\begin{array}{r}444 \\
4\end{array}$ & 1,267 & & \\
\hline
\end{tabular}

Source: Authors' calculations.

Note: Significance codes: $0.001=* * *, 0.01=* *, 0.05=*, 0.1=\bullet$

\section{Return on Average Equity}

\begin{tabular}{l|l|l|l} 
Estimate & Standard error & t-value & p-value
\end{tabular}

Sample of OECD banks (957 banks)

Lag(LoanlmpairmentCharge/TotalAssets,1) Lag(ProxyNPLStock/TotalAssets,1)

Lag(TotalEquity/TotalAssets,1)

Lag(RWAs/TotalAssets,1)

Lag(NetInterestIncome/TotalAssets,1)

Lag(TotalNonInterestOplncome/TotalAssets,1)

Lag(LiquidAssets/TotalAssets,1)

Lag(TotalCustomerDeposits/TotalAssets,1)

Lag(Longtermfunding/TotalAssets,1)

Lag(Loan.CustomerDeposit,1)

Lag(GrossLoanGrowth,1)

Year dummy for 2007

Year dummy for 2008

Year dummy for 2009

Year dummy for 2010

Root-squared: within, between and overall

Number of groups and observations

From 2007 to 2010

\begin{tabular}{|c|c|c|c|}
\hline$-1,754.7538$ & 123.4648 & -14.21 & $0.0000 * * *$ \\
\hline 395.0031 & 60.2978 & 6.55 & $0.0000 * * *$ \\
\hline-168.0256 & 60.9728 & -2.76 & $0.0060 * *$ \\
\hline-4.6233 & 11.3664 & -0.41 & 0.6843 \\
\hline 795.5429 & 250.0419 & 3.18 & $0.0015 * *$ \\
\hline 93.5276 & 135.8151 & 0.69 & 0.4912 \\
\hline 28.2402 & 14.9701 & 1.89 & $0.0596 \bullet$ \\
\hline 51.2948 & 16.5584 & 3.10 & $0.0020 * *$ \\
\hline 72.0967 & 17.6182 & 4.09 & $0.0000 * * * *$ \\
\hline-0.0003 & 0.0023 & -0.15 & 0.8845 \\
\hline-0.5005 & 2.2192 & -0.23 & 0.8216 \\
\hline-16.2603 & 7.6940 & -2.11 & $0.0350 *$ \\
\hline-25.4831 & 1.8081 & -5.10 & $0.0000 * * * *$ \\
\hline-23.6577 & 1.9121 & -3.87 & $0.0000 * * *$ \\
\hline-18.5681 & 2.0673 & -1.12 & 0.2640 \\
\hline 0.2665 & 0.0813 & 0.177 & \\
\hline $\begin{array}{r}444 \\
4\end{array}$ & 1,276 & & \\
\hline
\end{tabular}

Source: Authors' calculations.

Note: Significance codes: $0.001=* * *, 0.01=* *, 0.05=*, 0.1=\bullet$ 


\section{Equity Price}

\begin{tabular}{l|l|l} 
Estimate & Standard error & t-value
\end{tabular} p-value

Sample of OECD banks (957 banks)

Lag(LoanImpairmentCharge/TotalAssets,1) Lag(ProxyNPLStock/TotalAssets,1)

Lag(TotalEquity/TotalAssets,1)

Lag(RWAs/TotalAssets, 1 )

Lag(NetInterestlncome/TotalAssets,1)

Lag(TotalNonlnterestOplncome/TotalAssets,1)

Lag(LiquidAssets/TotalAssets,1)

Lag(TotalCustomerDeposits/TotalAssets,1)

Lag(Longtermfunding/TotalAssets,1)

Lag(Loan.CustomerDeposit,1)

Lag(GrossLoanGrowth,1)

Year dummy for 2007

Year dummy for 2008

Year dummy for 2009

Year dummy for 2010

Root-squared: within, between and overall

Number of groups and observations

From 2007 to 2010

\begin{tabular}{|r|r|r|l|}
\hline 21.1577 & 5.9573 & 3.55 & $0.0004 * * *$ \\
-2.3263 & 2.2681 & -1.03 & 0.3058 \\
3.5615 & 2.3079 & 1.54 & 0.1237 \\
0.0800 & 0.3810 & 0.21 & 0.8339 \\
-8.7091 & 7.5249 & -1.16 & 0.2479 \\
4.9954 & 4.0292 & 1.24 & 0.2159 \\
-0.8662 & 0.4894 & -1.77 & 0.0776 \\
0.6185 & 0.5839 & 1.06 & 0.2902 \\
-0.8976 & 0.5704 & -1.57 & 0.1165 \\
0.0721 & 0.0362 & 1.99 & $0.0469 *$ \\
-0.1916 & 0.0772 & -2.48 & 0.0135 \\
-0.3342 & 0.4292 & -0.78 & 0.4370 \\
-0.8146 & 0.0549 & -8.75 & $0.0000 * * *$ \\
-0.0518 & 0.0656 & 4.30 & $0.0000 * * *$ \\
-0.4029 & 0.0782 & -0.88 & 0.3810 \\
\hline 0.4843 & 0.1227 & 0.2555 & \\
\hline 209 & 56 & & \\
\hline 4 & & &
\end{tabular}

Source: Authors' calculations.

Note: Significance codes: $0.001=* * *, 0.01=* *, 0.05=* 0.1=\bullet$. 